Internat. J. Math. \& Math. Sci.

Vol. 24, No. 7 (2000) 433-435

S0161171200004634

(c) Hindawi Publishing Corp.

\title{
A SUBORDINATION THEOREM FOR SPIRALLIKE FUNCTIONS
}

\section{SUKHJIT SINGH}

(Received 24 November 1999)

AвSTRACT. We prove a subordination relation for a subclass of the class of $\lambda$-spirallike functions.

Keywords and phrases. Convex function, spirallike function, subordinating factor sequence.

2000 Mathematics Subject Classification. Primary 30C45; Secondary 30C50.

1. Introduction. Let $K$ denote the usual class of convex functions. Denote by $S_{p}(\lambda)$, $-\pi / 2<\lambda<\pi / 2$, the class of functions $f(z)=z+a_{2} z^{2}+\cdots$ which are analytic in $E$ and satisfy therein the condition

$$
\operatorname{Re}\left[e^{i \lambda} \frac{z f^{\prime}(z)}{f(z)}\right]>0 .
$$

Spacek [3] proved that members of $S_{p}(\lambda)$, known as $\lambda$ spirallike functions, are univalent in E. In 1989, Silverman [2] proved that if

$$
\sum_{n=2}^{\infty}[1+(n-1) \sec \lambda]\left|a_{n}\right| \leq 1 \quad\left(|\lambda|<\frac{\pi}{2}\right),
$$

then the function $f(z)=z+\sum_{n=2}^{\infty} a_{n} z^{n}$ belongs to $S_{p}(\lambda)$. Let us denote by $G(\lambda)$, the class of function $f(z)=z+\sum_{n=2}^{\infty} a_{n} z^{n}$ whose coefficients satisfy the condition (1.2). Note that $G(0)$ is a subclass of the class of starlike functions (with respect to the origin) (see Silverman [1]).

In this paper, we prove a subordination theorem for the class $G(\lambda)$. To state and prove our main result we need the following definitions and lemma.

DEFINITION 1.1. If $f(z)=\sum_{n=0}^{\infty} a_{n} z^{n}$ and $g(z)=\sum_{n=0}^{\infty} b_{n} z^{n}$ are analytic in $|z|<r$, then their Hadamard product/convolution, $f * g$ is the function defined by the power series

$$
(f * g)(z)=\sum_{n=0}^{\infty} a_{n} b_{n} z^{n} .
$$

The function $f * g$ is also analytic in $|z|<r$.

DEFINITION 1.2. Let $f$ be analytic in $E, g$ analytic and univalent in $E$ and $f(0)=$ $g(0)$. Then by the symbol $f(z) \prec g(z)$ ( $f$ subordinate to $g$ ) in $E$, we shall mean that $f(E) \subset g(E)$. 
DEFINITION 1.3. A sequence $\left\{\boldsymbol{b}_{n}\right\}_{1}^{\infty}$ of complex numbers is said to be a subordinating factor sequence if whenever $f(z)=\sum_{k=1}^{\infty} a_{k} z^{k}, a_{1}=1$ is regular, univalent and convex in $E$, we have

$$
\sum_{k=1}^{\infty} b_{k} a_{k} z^{k} \prec f(z) \quad \text { in } E .
$$

LEMMA 1.4. The sequence $\left\{b_{n}\right\}_{1}^{\infty}$ is a subordinating factor sequence if and only if

$$
\operatorname{Re}\left[1+2 \sum_{n=1}^{\infty} b_{n} z^{n}\right]>0, \quad(z \in E) .
$$

This lemma which gives a beautiful characterisation of a subordinating factor sequence is due to Wilf [4].

\section{Main theorem}

THEOREM 2.1. Let $f \in G(\lambda)$. Then

$$
\frac{1+\sec \lambda}{2(2+\sec \lambda)}(f * g)(z) \prec g(z), \quad(z \in E)
$$

for every function $g$ in the class $K$.

In particular

$$
\operatorname{Re} f(z)>-\frac{2+\sec \lambda}{(1+\sec \lambda)}, \quad(z \in E) .
$$

The constant $(1+\sec \lambda) / 2(2+\sec \lambda)$ cannot be replaced by any larger one.

Taking $\lambda=0$, we obtain the following corollary.

COROLLARY 2.2. If $f(z)=z+a_{2} z^{2}+\cdots$ is regular in $E$ and satisfies therein the condition

$$
\sum_{n=2}^{\infty} n\left|a_{n}\right| \leq 1
$$

then for every function $g$ in $K$, we have

$$
\frac{1}{3}(f * g)(z) \prec g(z), \quad(|z|<1) .
$$

In particular, $\operatorname{Re} f(z)>-3 / 2, z \in E$. The constant $1 / 3$ is best possible.

Proof OF THeORem 2.1. Let $f(z)=z+\sum_{n=2}^{\infty} a_{n} z^{n}$ be any member of the class $G(\lambda)$ and let $g(z)=z+\sum_{n=2}^{\infty} c_{n} z^{n}$ be any function in the class $K$. Then

$$
\frac{1+\sec \lambda}{2(2+\sec \lambda)}(f * g)(z)=\frac{1+\sec \lambda}{2(2+\sec \lambda)}\left(z+\sum_{n=2}^{\infty} a_{n} c_{n} z^{n}\right) \text {. }
$$

Thus, by Definition 1.3, the assertion of our theorem will hold if the sequence

$$
\left(\frac{(1+\sec \lambda) a_{n}}{2(2+\sec \lambda)}\right)_{n=1}^{\infty}
$$

is a subordinating factor sequence, with $a_{1}=1$. In view of the lemma, this will be the 
case if and only if

$$
\operatorname{Re}\left[1+2 \sum_{n=1}^{\infty} \frac{1+\sec \lambda}{2(2+\sec \lambda)} a_{n} z^{n}\right]>0, \quad(z \in E) .
$$

Now

$$
\begin{aligned}
\operatorname{Re}[1+ & \left.\frac{1+\sec \lambda}{2+\sec \lambda} \sum_{n=1}^{\infty} a_{n} z^{n}\right] \\
= & \operatorname{Re}\left[1+\frac{1+\sec \lambda}{2+\sec \lambda} z+\frac{1}{2+\sec \lambda} \sum_{n=2}^{\infty}(1+\sec \lambda) a_{n} z^{n}\right] \\
> & {\left[1-\frac{1+\sec \lambda}{2+\sec \lambda} r-\frac{1}{2+\sec \lambda} \sum_{n=2}^{\infty}(1+(n-1) \sec \lambda)\left|a_{n}\right| r^{n}\right] } \\
> & \quad\left(1-\frac{1+\sec \lambda}{2+\sec \lambda} r-\frac{1}{2+\sec \lambda} r\right] \quad(|z|=r) \\
> & 0 .
\end{aligned}
$$

Thus (2.7) holds true in $E$. This proves the first assertion. That $\operatorname{Re} f(z)>-(2+$ $\sec \lambda) /(1+\sec \lambda)$ for $f \in G(\lambda)$ follows by taking $g(z)=z /(1-z)$ in (2.1). To prove the sharpness of the constant $(1+\sec \lambda) / 2(2+\sec \lambda)$, we consider the function $f_{0}$ defined by $f_{0}(z)=z-(1 /(1+\sec \lambda)) z^{2}(|\lambda|<\pi / 2)$, which is a member of the class $G(\lambda)$. Thus from the relation (2.1) we obtain

$$
\frac{1+\sec \lambda}{2(2+\sec \lambda)} f_{0}(z) \prec \frac{z}{1-z} .
$$

It can be easily verified that

$$
\min _{|z| \leq 1} \operatorname{Re}\left[\frac{1+\sec \lambda}{2(2+\sec \lambda)} f_{0}(z)\right]=-\frac{1}{2} .
$$

This shows that the constant $(1+\sec \lambda) / 2(2+\sec \lambda)$ is best possible.

ACKNOWLEDGEMENT. This paper was presented at the 62 nd annual conference of the Indian Mathematical Society held at IIT, Kanpur from December 22-25, 1996.

The author is thankful to Prof. Ram Singh, Department of Mathematics, Punjabi University, Patiala, for his help and encouragement during this work.

\section{REFERENCES}

[1] H. Silverman, Univalent functions with negative coefficients, Proc. Amer. Math. Soc. 51 (1975), 109-116. MR 51\#5910. Zbl 311.30007.

[2] _ Sufficient conditions for spiral-likeness, Int. J. Math. Math. Sci. 12 (1989), no. 4, 641-644. MR 90k:30024. Zbl 688.30009.

[3] L. Spacek, Contribution à la theorie des fonctions univalents, Cas. Mat. Fys. 62 (1932), no. 2, 12-19 (Czech). Zbl 006.06403.

[4] H. S. Wilf, Subordinating factor sequences for convex maps of the unit circle, Proc. Amer. Math. Soc. 12 (1961), 689-693. MR 23\#A2519. Zbl 100.07201.

SUKHJIT Singh: DEPARTMENT OF MATHEMATICS, SANT LONGOWAL INSTITUTE OF ENGINEERING \& TeChNOLOGY, LONGOWAL-148 106 (PUnJAB), INDIA 


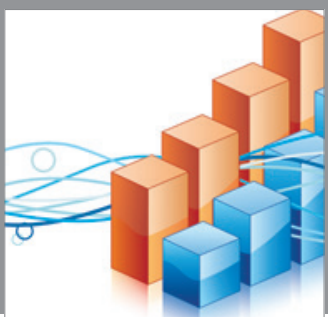

Advances in

Operations Research

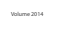

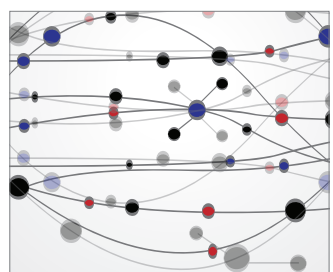

\section{The Scientific} World Journal


International Journal of

Mathematics and

Mathematical

Sciences
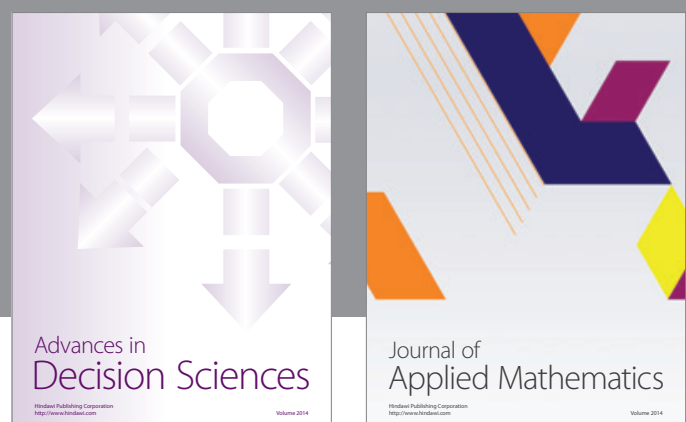

Journal of

Applied Mathematics
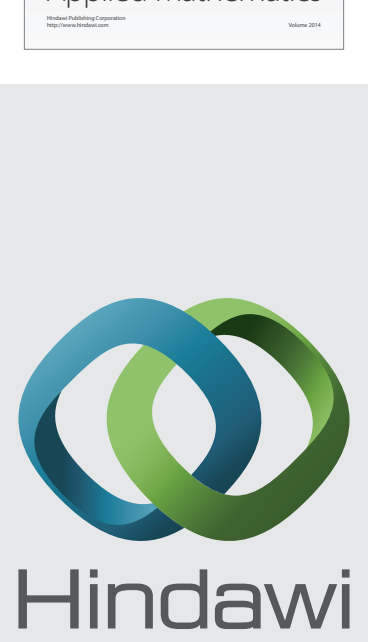

Submit your manuscripts at http://www.hindawi.com
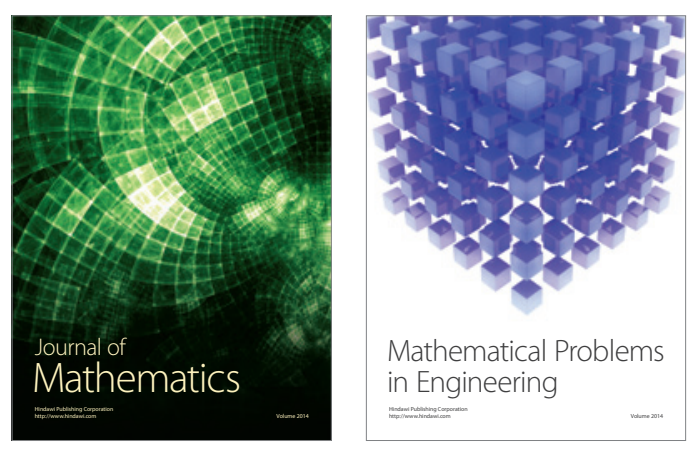

Mathematical Problems in Engineering
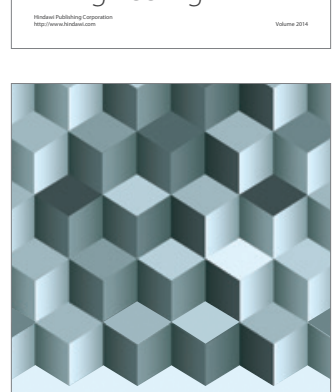

Journal of

Function Spaces
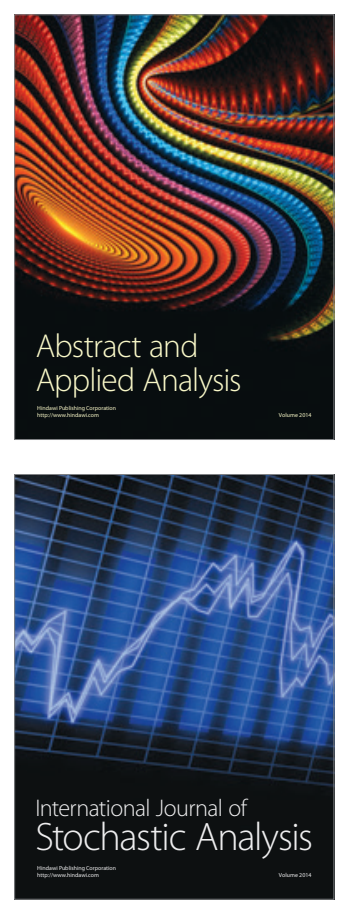

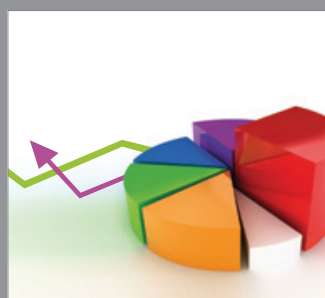

ournal of

Probability and Statistics

Promensencen
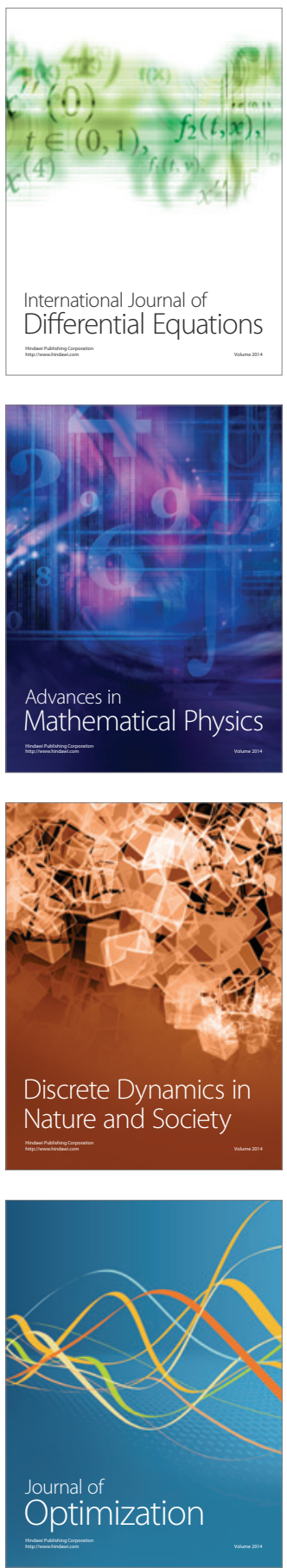